tion of the 'velocity-distance proportionality', often called Hubble's Law. This law underlies all modern theoretical cosmology and the concept of the expanding universe. Recent refinements due to Hubble himself have called in question the interpretation of the red-shifts as velocities; but, in whatever form, the apparent increase of velocity at the rate of about $500 \mathrm{~km}$. sec.-1 per $10^{\circ}$ parsecs is a fundamental worlddatum. Hubble's more recent researches have been concerned with the distribution of the nebulæ in space and the discovery of their average homogeneity, modified by a tendency to form groups and clusters; with the determination of the mean density of matter in space, another fundamental constant; with space absorption and obscuration in the galactic plane; with the effects of red-shifts on apparent magnitudes ; and with the character of the 'local' group of nebulæ. It may fairly be claimed that the modern picture of the universe of extra-galactic nebulæ is largely due to Hubble's researches. He has recently collected them in a book, "The Realm of the Nebulæ", a work of epic quality. His contributions are characterized by the power and originality of his methods, by his observational skill, by the objective character of his deductions and by the general brilliancy of his results.

\section{The Earthquake in Turkey}

THE first official estimate of the earthquake losses was given to the Kamutay on January 11 by the Health Minister, who said that there were 23,131 dead and 7,994 injured and that 29,131 houses had been ruined. Further news of the disaster comes from the affected areas as communications are restored. The Susheri distriet north-east of Erzinjan had been completely cut off for a fortnight except for the dropping of food and medicaments by a squadron of aeroplanes. There were 3,950 dead and 590 injured. It appears that the Malatia Erzinjan railway was not so greatly affected by the earthquake as the Sivas Erzinjan line, though the blizzards and snow affected this line tremendously. According to eye-witness accounts from Rechadiye, there were crevices 400 yards long and several yards wide in different directions. Streams and rivulets have changed their courses. At a place 12 kilometres from Rechadiye a mountain had its shape completely altered, giant precipices being formed and roads being blocked. The Yeshil-Irmak overflowed and further threatened Amasya.

Sailors report that between Kerasun and ShebinKarihisar an entire mountain has subsided. Photographs from Erzinjan show that movement there took place in all directions, as there appears to have been no predominant direction of fall of the columns and other debris. The town of Erbaa near Tokat has apparently suffered almost as much as Erzinjan, and in many places the bursting of drains due to the earthquake and floods has added new terror. It is reported that typhoid has broken out at Fatsa. Aftershocks of decreasing intensity have been felt at intervals in the widely separated areas of Samsun, Amasya, Bursa, Kersund, Yozgad, Inebolu, Bolu,
Burdur, Isparta, Karahisar, Erbaa, Akhissar, Odemish, Duzic, Sivas, Tokat, Bergama, Smyrna and Kikili, that is from northern to south-western Anatolia, according to a Times report.

The entire body of survivors from Erzinjan, numbering 3,200 , have been removed to Alexandretta, Mersin, Adana and other towns of Southern Anatolia, except about 130 injured, who have been placed in hospitals in Istanbul, and the surviving military cadets who have been sent to Konia. It is reported that the Government is discussing a proposal to rebuild Erzinjan on its present site, and temporary wooden cottages are to be erected. Dr. G. Van Dyk states that the first pulse to arrive at De Bilt (Holland) after the earthquake was dilatational, and that possible after-shocks were registered there on December 27 at $22 \mathrm{~h}$. $44 \mathrm{~m}$. 3s. G.M.T. and on December 28 at $3 \mathrm{~h} .30 \mathrm{~m}$. $45 \mathrm{~s}$. and $3 \mathrm{~h} .35 \mathrm{~m}$. $15 \mathrm{~s}$. G.M.T. We are indebted to Rev. J. P. Rowland, S.J., of the Stonyhurst College Observatory, for a copy of the seismogram of the principal earthquake. This seems to indicate the possibility of three distinct shocks having occurred within the first minute. They appear to have been of increasing intensity and from very nearly the same epicentre.

\section{Drug Standardization}

The Harrison Memorial Lecture was delivered by Mr. A. D. Powell, chief analyst of Boots Pure Drug Co., Ltd., at the evening meeting of the Pharmaceutical Society on January 9. His subject, "Drug Standardization", was chosen, he said, in token of the work done in that connexion by the late Colonel E. F. Harrison prior to his undertaking the responsibilities of his post as chief of the Defensive Gas Warfare Department during the War of 1914-18. Mr. Powell surveyed the progress of standardization from the time when, as a result of the disclosures of the Lancet Analytical Sanitary Commission, the Adulteration Act 1860 was passed, and concluded by outlining his own ideas of the desirable features of a satisfactory drug standard.

Mr. Powell put forward five points : (1) The description and principal requirements of strength should be free from ambiguity, and the descriptive paragraph, if it referred to a drug of definite chemical composition, should not be so restrictive as to insist on a particular method of preparation. (2) The degree of purity in terms of the substance, or of an active principle, should be defined wherever possible, unless, as with many organic chemicals, the melting point gave a sufficient indication of a high degree of purity. (3) The tests for purity should be diagnostic, and preferably capable of application under conditions varying within reasonable limits. (4) The number of tests for purity should cover all the impurities likely to be present in significant proportion, but should be limited by this consideration. (5) Tests to detect traces of unlikely impurities, or a redundance of tests for the same impurity, may weaken rather than strengthen a standard. In general, standardization should be definite and free from ambiguous interpretation; this should not 